\title{
Investigation of new Stilbazolium dye thin films deposited by Pulsed Laser Deposition
}

\author{
S. Sotirov ${ }^{1}$, M. Todorova ${ }^{2}$, M. Draganov ${ }^{3}$, P. Penchev², R. Bakalska ${ }^{2}$, V. Serbezov ${ }^{1,4}$ \\ ${ }^{1}$ Faculty of Physics, Plovdiv University, 24 Tzar Assen Str., 4000 Plovdiv, Bulgaria \\ ${ }^{2}$ Faculty of Chemistry, Plovdiv University, 24 Tzar Assen Str., 4000 Plovdiv, Bulgaria \\ ${ }^{3}$ Faculty of Biology, Plovdiv University, 2 T. Samodumov Str., 4000 Plovdiv, Bulgaria \\ ${ }^{4}$ Vascotec GmbH, Gewerbepark Keplerstr. 10/12, Gera, Germany
}

\begin{abstract}
In present work we report the analysis of thin films and targets from new stilbazolium dye E-4-(2-(4hydroxynaphthalen-1-yl)vinyl)-1-octylquinolinium iodide (D1) deposited by Pulsed Laser Deposition (PLD) technique using high power UV TEA $\mathrm{N}_{2}$ laser. The thin films are deposited onto substrates $-\mathrm{KBr}$, 316L SS alloy, optical glass and aluminum foil. The films were characterized by FTIR spectroscopy, bright field microscopy, fluorescence microscopy and atomic force microscopy (AFM) analysis. FTIR spectroscopic analysis of thin films and target material shows small differences between deposited films and native substance. The films are found to be homogeneous by AFM results and without any cracks and droplets on the surfaces. The present study demonstrates the ability of PLD technique to provide thin films from new stilbazolium dyes with good quality when they are applied as non-linear optical (NLO) organic materials on different type of substrates.
\end{abstract}

Keywords: Non-linear optical organic material; Stilbazolium dye; Pulsed Laser Deposition

\section{INTRODUCTION}

Organic non-linear optical (NLO) thin films with preliminary designed properties and structure are very attractive for applications as fast optical switches, modulators, devices for frequency mixing processes, sensors, integrated optical circuits for telecommunication and medium for optical computing ${ }^{1-3}$.

Thin films of complex organic materials have been deposited by conventional non-vacuum techniques, such as dip coating, spin coating, spray coating, electrochemical deposition, Langmuir-Blodgett method and vacuum methods such as electron beam evaporation, thermally assisted vacuum evaporation, organic molecular beam epitaxy ${ }^{4,5}$. The PLD technique is well known for deposition of complex inorganic thin films ${ }^{6}$.

Recently developed laser based methods, as matrix assisted laser evaporation (MAPLE) using high power UV excimer lasers and resonant infrared PLD (RIR PLD) using free electron laser (FEL), have been found to be very appropriate for deposition of complex organic materials, including polymers, biopolymers, proteins and living cells ${ }^{7}$. The intrinsic disadvantages of these techniques are the necessity to use frozen solutions of the organic compounds as MAPLE target and complex/expensive FEL as ablating source for RIR PLD.

Corresponding author:

E-mail address: serbezov@plov.net (V. Serbezov)

17th International School on Quantum Electronics: Laser Physics and Applications,

edited by Tanja Dreischuh, Albena Daskalova, Proc. of SPIE Vol. 8770, $87700 \mathrm{E}$

(C) 2013 SPIE · CCC code: $0277-786 X / 13 / \$ 18 \cdot$ doi: $10.1117 / 12.2011876$ 
Relatively low-cost preparation of organic NLO dyes, as well as their active optical properties have stimulated researchers for synthesis of new ones. Stilbazolium salts (hemicyanines) are well known as i) good second order NLO materials with a higher tendency to crystallize in noncentrosymmetric structures than dipolar covalent compounds; ii) fast optical response time; iii) high melting point compounds; iv) architectural flexibility for molecular design ${ }^{8}$. Some authors try to find a way of decreasing the spontaneous self alignment of hemicyanine molecules in the sol-gel fabricated film on silica and hence they expect an enhancement of second harmonic generation (SHG) intensity ${ }^{9}$. Recently, it was reported for the enhancement of $\mathrm{THz}$ emission by optical rectification on a hemicyanine-self-assembled monolayer deposited on the Au film ${ }^{10}$.

Compared with inorganic NLO materials, there are also some drawbacks to stilbazolium dyes, such as low mechanical strength and thermal stability, difficulty in large single-crystal growth. It should be noted that the highest known value of the SHG is measured for a stilbazolium dye, called DAST, which shows SHG intensity 2000 times that of urea standard ${ }^{8}$. DAST has been used already in several prototype photonic devices ${ }^{11-14}$ and for THz generation and detection ${ }^{15,16}$. In our previous work we have reported a new stilbazolium dye (E)-1-ethyl-4-(2-(4-hydroxynaphthalen-1-yl)vinyl) quinolinium bromide, possessing SHG more than 10000 times higher than the standard, which makes it an excellent NLO candidate for photonic applications ${ }^{17}$. To the best of our knowledge, it is the first deposition of hemicyanine dye by PLD method. These results inspired us to continue the investigations.

The aim of the present work is to study the chemical composition and the morphology of the surface of thin films obtained by PLD technique. The thin films are composed by new stilbazolium dye with larger $\pi$-conjugated electron system.

\section{EXPERIMENTAL}

\subsection{Film deposition}

The experimental set-up used for the thin film deposition is typical of the PLD technique and is similar with that described in ref. 18. For the needs of the deposition, an EMG 120 Lambda Physik UV TEA $\mathrm{N}_{2}$ laser at $337.1 \mathrm{~nm}$ with 5 ns pulse duration and repetition rate of $20 \mathrm{~Hz}$ was used (pulse energy- $5 \mathrm{~mJ}$ ). The laser beam was focused by means of a quartz short focus $\left(\mathrm{f}=5 \mathrm{~cm}\right.$ ) lens, while the laser fluence was varied from $200 \mathrm{~mJ} / \mathrm{cm}^{2}$ to $3.5 \mathrm{~J} / \mathrm{cm}^{2}$. The target holder was rotated with a speed up to $500 \mathrm{rev} / \mathrm{min}$ by high speed mini-motor stage fixed on a single axis scanner inside a vacuum chamber. Using of high speed rotation and scanning of target enabled uniform erosion of the target and deposition of the films on relatively large area, up to $10 \mathrm{~cm}^{2}$ without significant film's thickness gradient. The distance between the target and the substrate (S) was fixed at $4.5 \mathrm{~cm}$. The single bulk dye target was prepared with the aid of a hydraulic press (Perkin Elmer) with $1.2 \mathrm{~cm}$ diameter and $0.3 \mathrm{~cm}$ thickness. All the experiments were carried out at room temperature and vacuum of $10^{-3}$ mbar, which was achieved by using standard two stage rotary pumps. The microscope glass substrates ("Ilmglass" 20x20x0.22 mm), 316L SS alloy, and Al foil were cleaned in an ultrasound bath with pure acetone and ethanol, before the deposition process and were dried with technical nitrogen. Mono crystals $\mathrm{KBr}, \mathrm{NaCl}$ were used as substrates for the infrared spectroscopy. The choice of substrates was done in order to provide compatibility with NLO devices. The thickness of the deposited films ranged between $80-300 \mathrm{~nm}$, measured by interferometric method.

\subsection{Spectral measurements}

The UV-Vis spectrum $\left(1 \mathrm{~cm}\right.$ quartz cell and concentration $1 \times 10^{-5} \mathrm{M}$ was recorded on Perkin-Elmer Lambda 9 UVVIS/NIR spectrometer operating between 190 and $900 \mathrm{~nm}$ using solvent methanol spectroscopic quality (Uvasol, Merck). Fourier-transform infrared IR spectra were recorded with an IR spectrophotometer VERTEX 70 FT-IR spectrometer (Bruker Optics). The used attenuated total reflectance (ATR) accessory was MIRacle ${ }^{\mathrm{TM}}$ with a onereflection $\mathrm{ZnSe}$ element (Pike). Thin films onto $\mathrm{KBr}$ plate were analyzed with absorbance spectra and the depositions onto 316L SS alloy and aluminum foil by ATR spectra.

\subsection{Bright field and fluorescence microscopy measurements}

An optical study was performed by bright-field fluorescence microscopy (Nikon Eclipse 80i) with maximum magnification 400X and four standard filters in the case of fluorescent mode. Each Nikon triple band fluorescence set 
was optimized for use with DAPI and FITC in combination with either TRITC or Texas Red probes. The microscopic imaging was performed by DS Camera Control Unit DS-U2 and DS camera Head DS-Fi 1 with use of imaging software NIS-Elements F 2.30 .

\subsection{AFM measurements}

AFM study in the present work was performed by Veeco DI Nanoscope MultiMode V system (contact mode) with scan size: $10 \mu \mathrm{m} \times 10 \mu \mathrm{m}$ along $X Y$ axis and vertical range $Z$ axis - of $2.5 \mu \mathrm{m}$.

\section{RESULTS AND DISCUSSION}

\subsection{NLO organic dye synthesis}

The stilbazolium dye E-4-(2-(4-hydroxynaphthalen-1-yl)vinyl)-1-octylquinolinium iodide (D1) is synthesized by Knoevenagel condensation of 4-hydroxynaphtaldehyde and octyllepidinium iodide in the presence of basic catalyst piperidine. Figure 1 shows the chemical structure of the investigated compound.

The dye synthesis methodology is analogous to that one described in ref. 17. Polycrystalline sample of dye D1 suitable for deposition by the PLD technique is obtained by crystallization from methanol. The melting point $\left(233-4^{\circ} \mathrm{C}\right)$ for the target dye is sharp which indicates a high level of purity and a crystalline phase of the resulting salt.

On the figure 2 is presented the UV-Vis spectrum of dye D1 measured in methanol solution at concentration $1 \times 10^{-5}$ $\mathrm{mol} / \mathrm{L}$. The absorbance spectrum shows a band with $\lambda_{\max }=495 \mathrm{~nm}$, while that measured in fluorescence spectrum shows a maximum at $631 \mathrm{~nm}$. A very large Stokes's shift of $136 \mathrm{~nm}\left(4354 \mathrm{~cm}^{-1}\right)$ in methanol solution is observed. Generally, a large Stokes shift is attributed to the different charge distribution in the excited state compared to the ground state ${ }^{19,20}$. This large charge displacement is an indication of a large polarizability ${ }^{21,22}$. Therefore, the new stilbazolium dye can be interesting as a very promising material for NLO application.

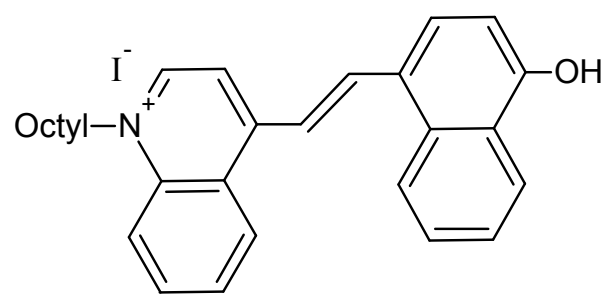

Figure 1. Chemical structure of the investigated dye D1.

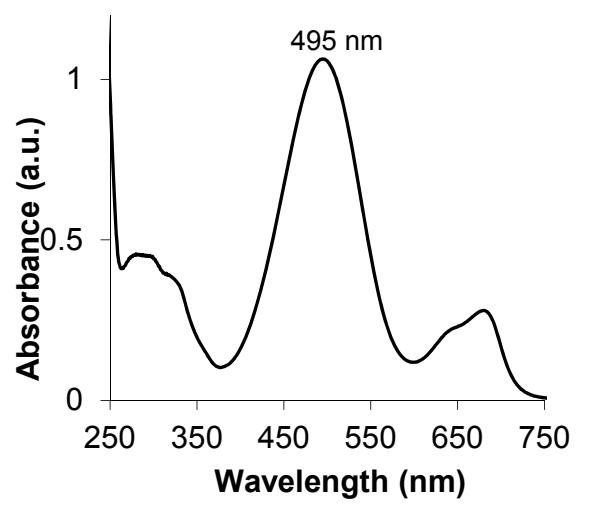

Figure 2. a) Absorption spectrum of dye D1 in methanol solution.

\subsection{FTIR spectral analysis}

The spectral analysis of the new stilbazolium dye deposited by PLD on various substrates is based on comparison of the spectral bands of the obtained thin films with those of the native materials in a region where most of the characteristic fundamental vibrations appear. For this study the $1700-600 \mathrm{~cm}^{-1}$ spectral interval is selected as it includes the finger print region and the region of aromatic ring vibrations. The spectral analysis will be illustrated with the detail comparison of two spectra of hemicyanine dye D1. 
The 1700-600 $\mathrm{cm}^{-1}$ region of the IR spectrum of dye D1 deposited onto KBr plate is shown in figure 3 (spectral line in red) together with the spectrum of a drop of dye methanol solution dried onto AgBr plate (spectral line in blue).

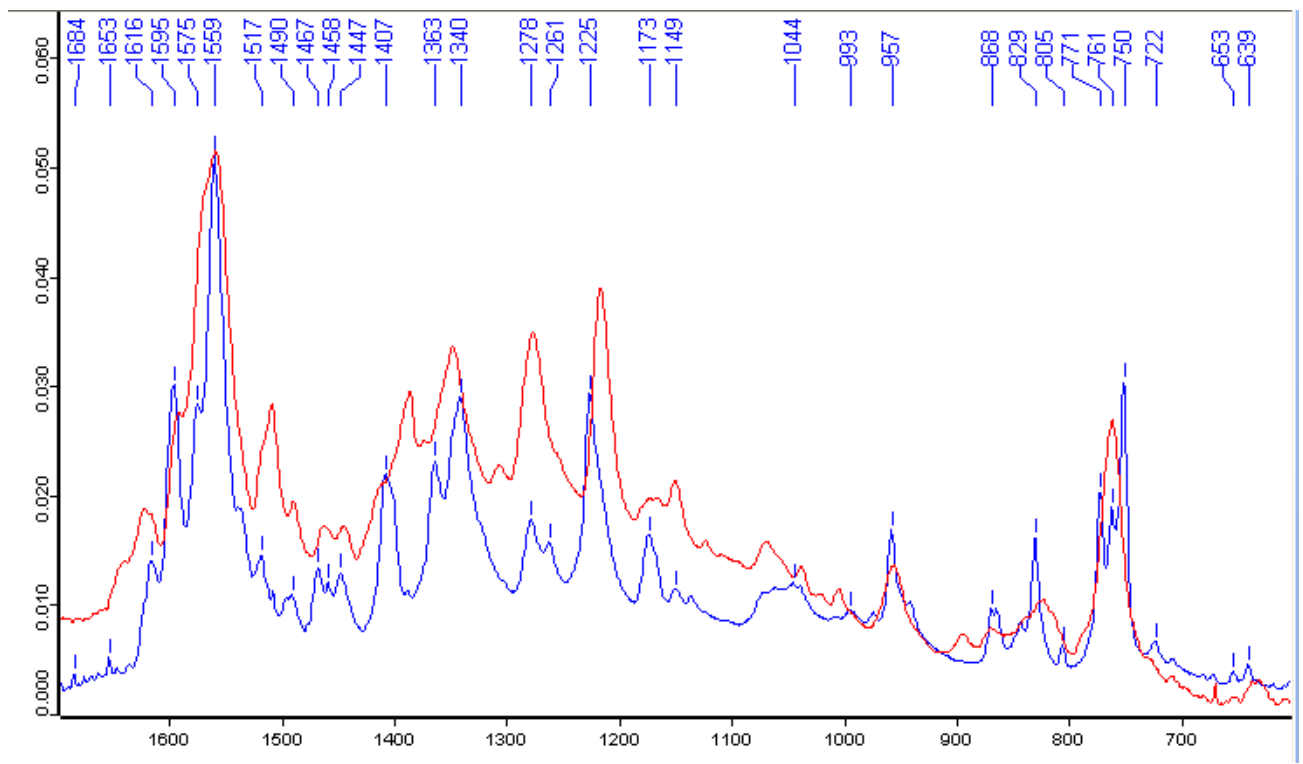

Figure 3. IR Absorbance spectra of dye D1: the spectral line in red is the spectrum of thin film (the substrate is a KBr plate), and the spectral line in blue -that of a drop of dye D1's methanol solution dried onto AgBr plate.

It can be seen that the two spectral curves look pretty similar and the bands of dye D1 at $1559 \mathrm{~cm}^{-1}, 1340 \mathrm{~cm}^{-1}, 1278 \mathrm{~cm}^{-1}$ and $957 \mathrm{~cm}^{-1}$ are preserved in the spectrum of the thin film. The most prominent IR-bands at $1559 \mathrm{~cm}^{-1}$ and $1595 \mathrm{~cm}^{-1}$ correspond to the strongly coupled $v_{\mathrm{C}=\mathrm{C}}$ and $8 \mathrm{a}, 8 \mathrm{~b}$ in-plane vibrations of the quinolinium fragment in the molecule ${ }^{17}$. These are the characteristic bands that are strongly influenced by the charge redistribution effects. On the other side, some of the bands are shifted up to $10 \mathrm{~cm}^{-1}$, which is to be expected as the compound is embedded into the crystal structure of $\mathrm{KBr}$. The strong bands of this type are $1225 \mathrm{~cm}^{-1}$ (in plane deformation vibration of quinolinium moiety) shifted to $1216 \mathrm{~cm}^{-1}$ and $750 \mathrm{~cm}^{-1}$ (skeleton deformation vibrations of both, quinolinium and naphthalene fragments) shifted to $760 \mathrm{~cm}^{-1}$, respectively. The interaction of the deposited dye with the substrate is also a reason for widening of most of the bands. In this case two or three bands close in the compounds spectrum can appear as one (usually unsymmetrical) band in the thin film spectrum. In figure 3 these are $1595 \mathrm{~cm}^{-1}$ and $1559 \mathrm{~cm}^{-1}$ couple, $1363 \mathrm{~cm}^{-1}$ and $1340 \mathrm{~cm}^{-1}$ couple and $771 \mathrm{~cm}^{-1}, 761 \mathrm{~cm}^{-1}$ and $750 \mathrm{~cm}^{-1}$ triad.

There are two bands in the spectrum of the deposited compound that cannot be explained as a result of deposition - these are the strong $1508 \mathrm{~cm}^{-1}$ band and the $1149 \mathrm{~cm}^{-1}$ band. The only explanation is that a partial degradation of the deposited compound happened.

As a whole, the high laser fluence $\left(3.5 \mathrm{~J} / \mathrm{cm}^{2}\right)$ used for dye deposition has not decomposed heavily the target material. The high fluence shortens the deposition process thus decreasing its cost.

\subsection{Surface analysis}

An optical and optical fluorescent analyses were performed of thin films of the investigated new stilbazolium dye D1 deposited onto substrates from $\mathrm{KBr}, 316 \mathrm{~L}$ SS alloy, optical glass and aluminum foil.

As can be seen from figure 4, polycrystalline layers grown on aluminum foil substrate from the vapor phase under vacuum usually exhibit a uniform "single-crystal-like" orientation. Optical micrographs show that the layers are essentially polycrystalline. However, the numerous crystals composing the layers show the same morphology and the same orientation with respect to the $\mathrm{Al}$ foil sliding direction (figure $4 \mathrm{~b}$ ). The arrow shows the clean surface of the substrate indicating the $\mathrm{Al}$ foil sliding direction. These micrographs clearly indicate that a specific nucleation occurs at 
the ordered Al foil surface giving very likely a peculiar crystallographic plane in contact with the substrate. The average orientation of these crystals will be deduced from powder X-ray diffraction in our future work.

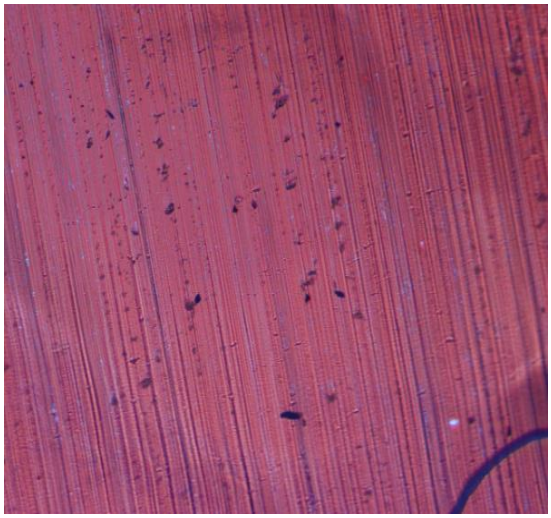

a)

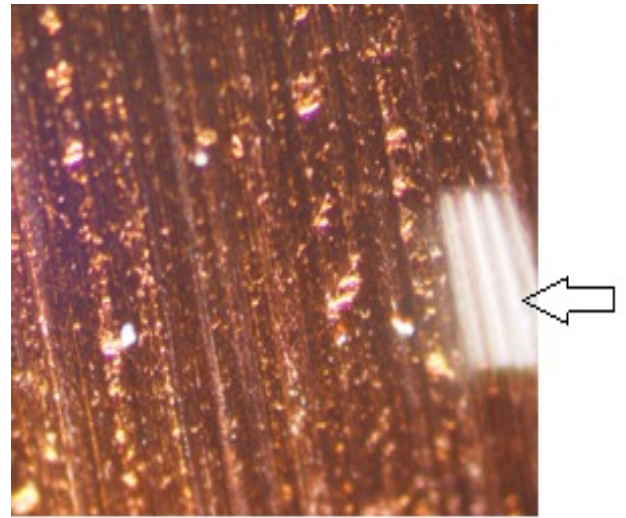

b)

Figure 4. Optical micrographs of the D1 thin film on aluminum foil substrate: a) 100X; b) 200X. The arrow shows the clean surface of the substrate indicating the $\mathrm{Al}$ foil sliding direction.

The surface quality of thin film of dye D1 onto samples from stainless steel 316L are shown on figure 5. A similar orientation, such as the above mentioned one, is observed in layers with thickness $180 \mathrm{~nm}$ on a stainless steel substrate (figures $5 \mathrm{a}$ and $5 \mathrm{c}$ ). The arrow shows the clean surface of the substrate indicating the stainless steel sliding direction. When the thickness of layers increases, a completely disordered structure can be observed (figure 5b). It is known that the NLO properties of the crystalline layers depend of their molecular orientation ${ }^{23,24}$.

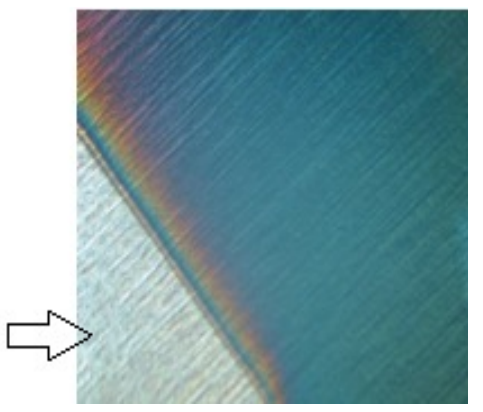

a)

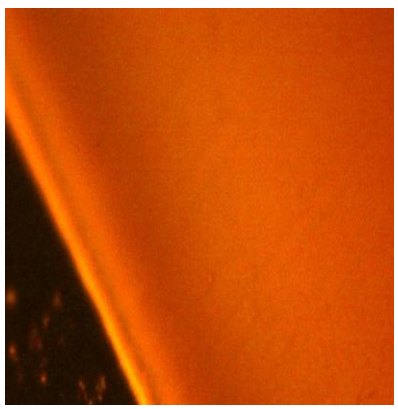

b)

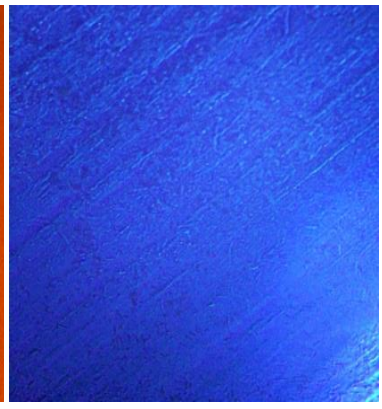

c)

Figure 5. Bright field and fluorescence micrographs of dye D1 as thin film onto samples from stainless steel 316L: a) 100X; b) 200X by filter Texas Red; c) $200 X$ by filter DAPI. The arrow shows the clean surface of the substrate indicating the stainless steel sliding direction.

AFM is useful tool for studying surfaces because it may provide real volumetric film morphology and nanostructures. Figures 6 and 7 show the ability of AFM to visualize and characterize surfaces of the stilbazolium dye D1 deposited by PLD on glass substrates and aluminum foils with thickness $220 \mathrm{~nm}$, respectively. $X$ and $Y$ axes are graduated in $\mu \mathrm{m}$ and show the area of the scanned sample. $Z$ axis is graduated in $\mathrm{nm}$ and shows the roughness of the sample. 
The surface topology showed a different mode of the growing of crystals in the deposited films in relation to substrates nature. The film on glass substrate is extremely uniform with deviation of no more than $20 \mathrm{~nm}$ (figure 6), while that one deposited onto aluminum foil showed a deviation of more than $30 \mathrm{~nm}$ (figure 7) and preference for growing in vertical axis. The crystal structure of aluminum foil defines the direction of deposited film ${ }^{23}$. The films have highly-ordered uniform morphology and a layered structure; the organic molecules stand nearly vertical in the case of metal (aluminium foil) substrates and planar in the case of dielectric substrates, such as optical glass and mono crystals from $\mathrm{KBr}$.

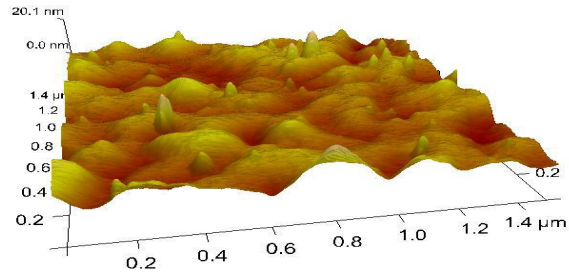

Figure 6. AFM 3D image of a surface of the thin film of dye D1 deposited by PLD on glass substrate.

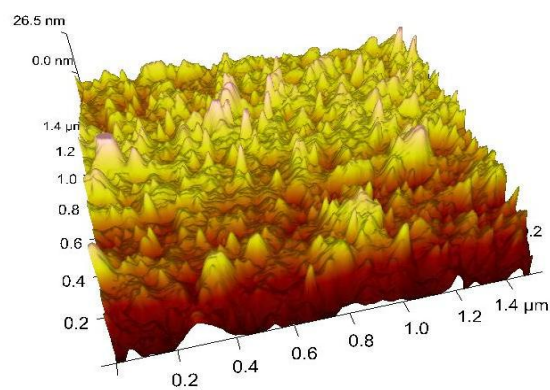

Figure 7. AFM 3D image of a surface of the thin film of dye D1 deposited by PLD on aluminum foil.

\section{CONCLUSION}

A successful deposition of thin films from stilbazolium dye with larger conjugated system than the well-known DAST is described. The thin-film deposition technique is PLD using high power UV $\mathrm{N}_{2}$ laser. The films have highly-ordered uniform morphology and a layered structure. They are homogeneous and their surface has a roughness of no more than $40 \mathrm{~nm}$ which is still enough and compatible for NLO applications. This preliminary study and the previous one ${ }^{17}$ afford an interesting possibility to compose new stilbazolium dye - inorganic nanocomposites for direct photonics applications.

\section{Acknowledgements}

All experiments of PLD were done with a kind cooperation of Vascotec GmbH. R.B and M.T. thank the Research Investigations Fund of the University of Plovdiv (project 11 FC 007), for financial support. P.P. thanks the National Research Fund of Bulgaria (Grant DDWU-02-37). The participation in 17ISQE 2012 was supported by FP7 BioSupport project.

\section{REFERENCES}

[1] Chemla, D. S., Zyss, J., [Nonlinear Optical Properties of Organic Molecules and Crystals], Academic Press, Ontario (1987).

[2] Kajzar, F., [Organic Thin Films for Waveguiding Nonlinear Optics], In Advances in Nonlinear Optics, vol. 3, Taylor \& Francis (1996).

[3] Trager, F. (Ed.), [Handbook of Lasers and Optics], Springer Science\&Business Media, LLC New York (2007).

[4] Sanches, C.; Lebean, B.; Chaput, F.; Boilot, J. P., "Optical properties of functional hybrid organic-inorganic nanocomposites", Adv. Mater. 15, 1969-1994 (2003). 
[5] Quintel, A., Budde, F., Rechsteiner, P., Thoma, K., Zayatsb, A., Hulliger, J., „Molecular beam deposition of crystalline layers of polar perhydrotriphenylene inclusion compounds characterised by second harmonic generation microscopy“, J. Mater. Chem. 10, 27-30 (2000).

[6] Serbezov, V., Review: "Pulsed Laser Deposition: The Road to Hybrid Nanocomposite Coatings and Novel Pulsed Laser Adaptive Technique", Recent Patents on Nanotechnology, NANOTEC, 6 (3) (2012), in press

[7] Chrisey, D. B.; Pique, A.; McGill, R. A.; Horwiz, J. S.; Ringeisen, B. R.; Bubb, D. B.; Wu, P. K., "Laser Deposition of Polymer and Biomaterial Films", Chem. Rev. 103, 553-576 (2003).

[8] Nalwa, H. S., Watanabe, T., Miyata, S., [Organic Materials for Second-Order Nonlinear Optics in Nonlinear Optics of Organic Molecules and Polymers], Chapter 4, Nalwa, H. S., Miyata, S., Eds. CRC Press: Boca Raton, FL, 89-351 (1997).

[9] Xu, L., Liu, L., Yu, J., Wang, W., Li, F., Zhang, Z., "Spontaneous self alignment and structural changes of unpoled hemicyanine dopant in silica film", Proc. SPIE, 3136, Sol-Gel Optics IV, Washington, 62-65 (1997).

[10] Ramakrishnan, G., Kumar, N., Planken, P. C. M., Tanaka, D., Kajikawa, K., "Surface plasmon-enhanced terahertz emission from a hemicyanine self-assembled monolayer", OPT. EXPRESS 20(4), 4067-4073 (2012).

[11] Bosshard, Ch., Sutter, K., Prêtre, Ph., Hulliger, J., Flörsheimer, M., Kaatz, P., Günter, P., Organic Nonlinear Optical Materials, Vol. 1 of [Advances in Nonlinear Optics], eds. Garito, A.F. and Kajzar, F., Gordon and Breach Publishers (1995).

[12] Zyss, J., [Molecular Nonlinear Optics: Materials, Physics, and Devices], Academic Press, New York (1994).

[13] Marder, S. R., Stucky, G. D., Sohn, J. E., [Materials for Nonlinear Optics: Chemical Perspectives], Eds. ACS Symposium Series 455, American Chemical Society: Washington, DC (1991).

[14] Marder, S. R., Perry, J. W., Yakymyshyn, C. P., "Organic salts with large second-order optical nonlinearities", Chem. Mater. 6, 1137- 1147 (1994).

[15] Marder, S. R., Perry, J. W., Schaefer, W. P., "Synthesis of organic salts with large second-order optical nonlinearities", Science, 245, 626-628 (1989).

[16] Pan, F., Wong, M. S., Bosshard, Ch., Günter, P., "Crystal growth and characterization of the organic salt 4-N, Ndimethylamino-4'-N-methyl-stilbazolium tosylate (DAST)", Adv. Mater. 8, 592-595 (1996).

[17] Ouazzani, H. El, Dabos-Seignon, S., Gindre, D., Iliopoulos, K., Todorova, M., Bakalska, R., Penchev, P., Sotirov, S., Kolev, T., Serbezov, V., Arbaoui, A., Bakasse, M., Sahraoui, B., "Novel styrylquinolinium dye thin films deposited by pulsed laser deposition for nonlinear optical applications", J. Phys. Chem.C 116, 7144-7152 (2012).

[18] Serbezov,V., Benacka, St., Hadgiev, D., Atanasov, P., Elektronov, N., Smatko, V., Stribik, V., Vassilev, N., "Structure and superconducting properties of $\mathrm{YBa} 2 \mathrm{Cu} 3 \mathrm{O} 7-\mathrm{x}$ films prepared by nitrogen laser evaporation and $\mathrm{CO} 2$ laser annealing in oxygen", J. Appl. Phys. 67, 6953 -6957 (1990).

[19] Narag, U., Zhao, C. F., Bhawalkar, J. D., Bright, F. V., Prasad, P. N., „Characterization of a new solvent-sensitive two-photon-induced fluorescent aminostyrylpyridinium salt dye", J. Phys. Chem. 100, 4521-4525 (1996).

[20] Zhao, C. F., Gvishi, R., Narag, U., Ruland, G., Prasad, P. N., "Structures, spectra, and lasing properties of new aminostyrylpyridinium laser dyes", J. Phys. Chem. 100, 4526-4532 (1996).

[21] Binnemans K., Bex C., Venard A., De Leebeeck H., Görller-Walrand C., "Solvatochromism of lanthanide complexes containing the hemicyanine chromophore", J. Mol. Liq. 83, 283-294 (1999).

[22] Bruni, S., Cariati, E., Cariati, F., Porta, F. A., Quici, S., Roberto, D., "Determination of the quadratic hyperpolarizability of trans-4-[4-(dimethylamino)styryl]pyridine and 5-dimethylamino-1,10-phenanthroline from solvatochromism of absorption and fluorescence spectra: a comparison with the electric-field-induced second-harmonic generation technique" Spectrochim. Acta A 57, 1417-1426 (2001).

[23] Damman, P., Vallée, R., Dosière, M., Toussaere, E., Zyss, J., “Oriented crystallization of organic NLO materials", Synthetic Met. 124, 227-232 (2001).

[24] Komatsu, K., Nanjo, H., Yamagishi, Y., Kaino, T., "Oriented thin film fabrication of organic non-linear optical crystals", Thin Solid Films 393, 1-6 (2001). 